\title{
Organic Nanovesicular Cargoes for Sustained Drug Delivery: Synthesis, Vesicle Formation, Controlling "Pearling" States, and Terfenadine Loading/Release Studies
}

\author{
Ajay Kumar Botcha, ${ }^{1}$ Balakrishna Dulla, ${ }^{2}$ E. Ramanjaneya Reddy, ${ }^{2}$ \\ Keerthana S. Chennubhotla, ${ }^{3}$ Pushkar Kulkarni, ${ }^{3,4}$ \\ Rajadurai Chandrasekar, ${ }^{1}$ and Marina S. Rajadurai ${ }^{2}$ \\ ${ }^{1}$ Functional Molecular Nano/Micro Solids Laboratory, School of Chemistry, University of Hyderabad, Hyderabad 500046, India \\ ${ }^{2}$ Organic \& Medicinal Chemistry, Dr. Reddy's Institute of Life Sciences, University of Hyderabad Campus, Hyderabad 500046, India \\ ${ }^{3}$ Biology Department, Dr. Reddy's Institute of Life Sciences, University of Hyderabad Campus, Hyderabad 500046, India \\ ${ }^{4}$ Zephase Therapeutics, Dr. Reddy's Institute of Life Sciences, University of Hyderabad Campus, Hyderabad 500046, India
}

Correspondence should be addressed to Pushkar Kulkarni; kk.pushkar@gmail.com, Rajadurai Chandrasekar; chandrasekar100@yahoo.com and Marina S. Rajadurai; marinar@drils.org

Received 25 February 2014; Accepted 7 June 2014; Published 12 August 2014

Academic Editor: Paresh Chandra Ray

\begin{abstract}
Copyright (C) 2014 Ajay Kumar Botcha et al. This is an open access article distributed under the Creative Commons Attribution License, which permits unrestricted use, distribution, and reproduction in any medium, provided the original work is properly cited.

"Sustained drug delivery systems" which are designed to accomplish long-lasting therapeutic effect are one of the challenging topics in the area of nanomedicine. We developed an innovative strategy to prepare nontoxic and polymer stabilized organic nanovesicles (diameter: $200 \mathrm{~nm}$ ) from a novel bolaamphiphile, where two hydrogen bonding acetyl cytosine molecules connected to $4,4^{\prime \prime}$ positions of the 2,6-bispyrazolylpyridine through two flexible octyne chains. The nanovesicles behave like biological membrane by spontaneously self-assembling into "pearl-like" chains and subsequently forming long nanotubes (diameter: $150 \mathrm{~nm}$ ), which further develop into various types of network-junctions through self-organization. For drug loading and delivery applications, the nanovesicles were externally protected with biocompatible poly(ethyleneglycol)-2000 to prevent them from fusion and ensuing tube formation. Nontoxic nature of the nanovesicles was demonstrated by zebrafish teratogenicity assay. Biocompatible nanovesicles were loaded with "terfenadine" drug and successfully utilized to transport and release drug in sustained manner (up to $72 \mathrm{~h}$ ) in zebrafish larvae, which is recognized as an emerging in vivo model system.
\end{abstract}

\section{Introduction}

Synthetic nano-/microscale vesicles are of great interest because they emulate complex properties of biological cell membranes [1-4]. Most of the biological membranes are flexible; therefore they show multidimensional shape transformation to form zero-dimensional (0D) microspheres, one dimensional (1D) cylinders, and long flexible tubular structures. Hence mimicking the properties of naturally occurring vesicles by polymer, peptide, or dendrimer based synthetic vesicles is of great interest since they are potential tool for nanomedicine, biosensors, and biophysical and bioelectronic applications [5-8]. For instance, in the budding area of nanomedicine, nontoxic vesicles act as tiny spherical containers for storage and delivery of chemicals/reagents in biochemical reactions. Nanodrug delivery systems protect drug from degradation and deliver drug at specific sites thereby increasing efficacy of treatment $[5,9,10]$. Sometimes, multiple vesicles fuse due to the interaction of surface molecules between many vesicle membranes, a phenomenon known as "pearling," which leads to the formation of nanotubular vesicles (NTVs) [11]. Synthetic NTVs are also proposed for the transportation of chemicals between vesicles. Hence laboratory synthesis of nontoxic bioinspired molecules capable 

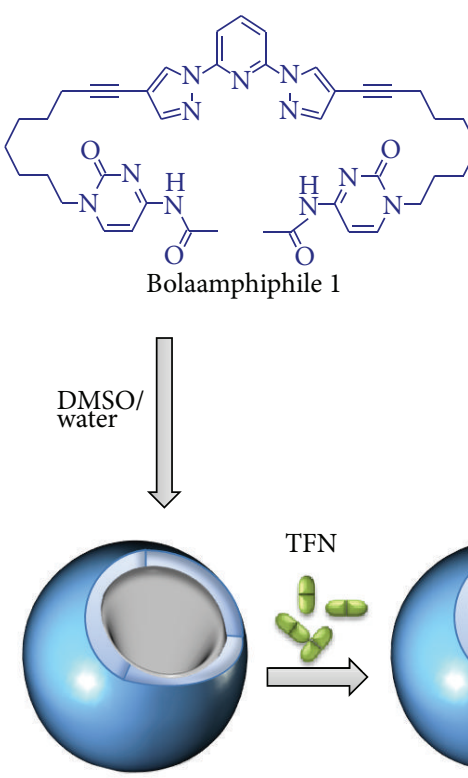

Vesicles
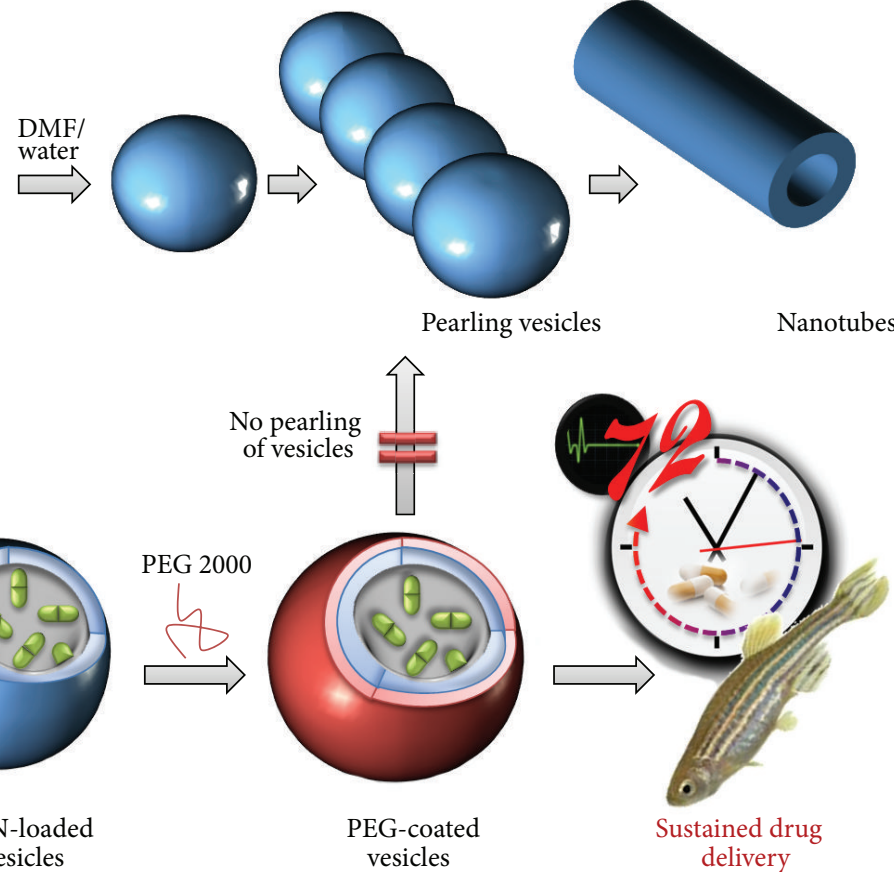

FIGURE 1: Illustration of the nanovesicles formation from bolaamphiphile $\mathbf{1}$ and their subsequent self-assembly into pearl chains and finally nanotubes. The nontoxic vesicles fusion (pearling) is prevented by biocompatible polymer coating and used in terfenadine (TFN) drug delivery in a sustained manner $(72 \mathrm{~h})$ in zebrafish model system.

of mimicking the biological membrane is a challenging task, since they can act as life-saving drug delivery and sustained drug release cargoes. Although a plethora of block copolymer based vesicles are explored for drug delivery applications [5], vesicles from small biologically inspired designer molecules are rare. Earlier, we have found that aromatic rigid core 2,6bispyrazolylpyridine (BPP) connected with long alkyl groups forms vesicles [12]. Hence for drug loading application the use of rigid molecules decorated with one of the base pairs found in DNA and RNA is a promising starting point to achieve nontoxic drug delivery systems. One of the ingredient problems with soft vesicles is their tendency to form tubes through fusion mechanism.

In this paper we present our strategy to prepare nontoxic and polymer stabilized vesicles from a novel bolaamphiphile 1 , that is, two hydrogen bonding N4-acetyl cytosine molecules connected to $4,4^{\prime \prime}$-positions of the BPP using two flexible octyne chains. The vesicles are loaded with terfenadine drug and successfully utilized to transport and release drugs in zebrafish larvae, which is utilized as an emerging in vivo model system (Figure 1). In this paper we present the synthesis of $\mathbf{1}$ and prevention of fusion driven nanotube formation by protecting the nanovesicles (NV) with biocompatible PEG 2000, terfenadine (TFN) drug loading, and its sustained drug releasing tendency. The nanovesicles were thoroughly characterized using scanning electron microscope (SEM), transmission electron microscope (TEM), and atomic force microscopy (AFM).

\section{Materials and Methods}

2.1. Synthesis of Compound 1. Molecule 1 was synthesized in six steps from BPP (Scheme 1); compound 2 was synthesized as per our reported procedure $[13,14]$.

10,10' -(1,1'-(Pyridine-2,6-diyl)bis(1H-pyrazole-4,1-diyl))bis(dec9-yn-1-ol) (3). Compound 2 (0.5 g, $1.07 \mathrm{mmol}), \mathrm{Pd}\left(\mathrm{PPh}_{3}\right)_{2} \mathrm{Cl}_{2}$ $(0.075 \mathrm{~g}, 0.106 \mathrm{mmol}), \mathrm{PPh}_{3}(0.050 \mathrm{~g}, 0.214 \mathrm{mmol})$, CuI $(0.027 \mathrm{~g}, 0.144 \mathrm{mmol})$ were taken in a $100 \mathrm{~mL}$ two-neck round bottom flask. To this solid mixture, high vacuum was applied through condenser for deoxygenating. Subsequently, solvents dry triethylamine $(15 \mathrm{~mL}), 1,4$ dioxane $(3 \mathrm{~mL})$, was added to the deoxygenated solid mixture under $\mathrm{N}_{2}$ atmosphere. After five minutes, 9-dec-yn-1-ol $(0.217 \mathrm{~g}, 1.41 \mathrm{mmol})$ was added and stirred for $8 \mathrm{~h}$ under $\mathrm{N}_{2}$ atmosphere at $80^{\circ} \mathrm{C}$. The solvents were removed under reduced pressure and solid product was purified by column chromatography using 5\% methanol/DCM. After washing the compound with diethyl ether, pure 3 was obtained as a white solid $(80 \%$ yield). ${ }^{1} \mathrm{H}-\mathrm{NMR}\left(400 \mathrm{MHz}, \mathrm{CDCl}_{3}\right): \delta=8.6(\mathrm{~s}, 2 \mathrm{H}), 7.9(\mathrm{~m}$, $1 \mathrm{H}), 7.8(\mathrm{~d}, 2 \mathrm{H}), 7.7(\mathrm{~s}, 2 \mathrm{H}), 3.6\left(\mathrm{~m}, 2 \mathrm{H},-\mathrm{OCH}_{2}\right), 2.4(\mathrm{~m}$, $4 \mathrm{H}), 1.6(\mathrm{~m}, 12 \mathrm{H}), 1.4(\mathrm{~m}, 12 \mathrm{H}) \mathrm{ppm} .{ }^{13} \mathrm{C}-\mathrm{NMR}(100 \mathrm{MHz}$, $\left.\mathrm{CDCl}_{3}\right): \delta=149.4,144.6,141.5,129.0,109.5,106.5,92.6,70.6$, 62.9, 32.7, 31.9, 29.7, 29.2, 28.8, 25.7, 22.6, 19.4 ppm. FT-IR (KBr): 3616.86, 3398.88, 3146.18, 3055.52, 2928.21, 2851.05, $1726.45,1601.06,1481.46,1497.1,1402.38,1354.15,1265.42$, $1219.12,1186.33,1055.16,1028.15,972.21,952.92,896.98$, 864.19, 800.53, 738.80, 706.01, 655.86. LC-MS analysis $m / z$ : 


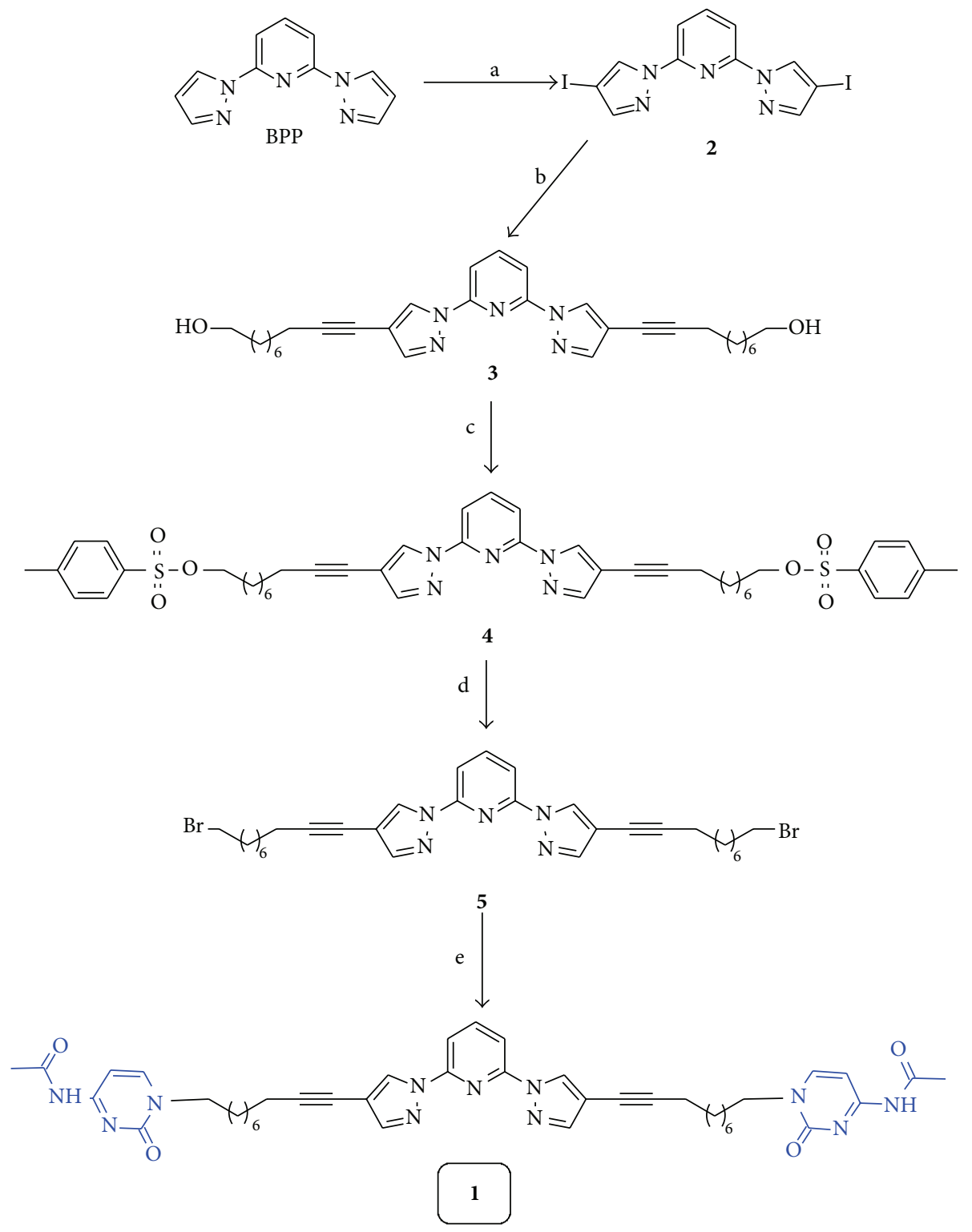

Scheme 1: Synthesis of cytosine decorated to 2,6-bispyrazolyl-pyridine derivative (1). General reaction conditions: (a) as per reported procedure [13, 14]; (b) 2 (1.07 mmol), $\mathrm{Pd}\left(\mathrm{PPh}_{3}\right)_{2} \mathrm{Cl}_{2}$ (0.106 mmol), $\mathrm{PPh}_{3}(0.21 \mathrm{mmol}), \mathrm{CuI}(0.14 \mathrm{mmol}), \mathrm{Et}_{3} \mathrm{~N} / 1,4$ dioxane, $\mathrm{N}_{2}$, 9-dec-yn-1ol (1.41 mmol), $80^{\circ} \mathrm{C}, 8 \mathrm{~h}, 80 \%$; (c) 3 (0.58 mmol), tosyl chloride (2.32 mmol), DCM/NEt ${ }_{3}, \mathrm{RT}, 2 \mathrm{~h}, 75 \%$; (d) 4 (0.24 mmol), LiBr (0.97 mmol), dry acetone, RT, $2 \mathrm{~h}, 89 \%$; (e) $\mathrm{N}^{4}$-acetyl cytosine $(1.40 \mathrm{mmol}), \mathrm{K}_{2} \mathrm{CO}_{3}(1.81 \mathrm{mmol})$, dry DMF, $5(0.47 \mathrm{mmol}), 80^{\circ} \mathrm{C}, 16 \mathrm{~h}, 55 \%$.

experimental value $=515.0$, calculated value $=514.2$. Anal. Calcd. for $\mathrm{C}_{31} \mathrm{H}_{41} \mathrm{~N}_{5} \mathrm{O}_{2}$ : C, 72.20; $\mathrm{H}, 8.01 ; \mathrm{N}, 13.58$ found: C, 72.36; H, 8.12; N, 13.49 .

10,10'-(1,1'-(Pyridine-2,6-diyl)bis(1H-pyrazole-4,1-diyl))bis(dec9-yne-10,1-diyl)bis(4-methylbenzene-sulfonate) (4). To the suspension solution of $\mathbf{3}(0.3 \mathrm{~g}, 0.58 \mathrm{mmol})$ in DCM $(15 \mathrm{~mL})$ and $\mathrm{NEt}_{3}(5 \mathrm{~mL})$, tosyl chloride $(0.443 \mathrm{~g}, 2.32 \mathrm{mmol})$ was slowly added. The reaction mixture was stirred for $2 \mathrm{~h}$ at room temperature. All the solvents were evaporated under reduced pressure and crude was purified by column chromatography with EtOAc/hexane (2:8). Colorless solid compound 4 was obtained in $75 \%$ yield. ${ }^{1} \mathrm{H}-\mathrm{NMR}(400 \mathrm{MHz}$, $\left.\mathrm{CDCl}_{3}\right): \delta=8.5(\mathrm{~s}, 2 \mathrm{H}), 7.9(\mathrm{~m}, 1 \mathrm{H}), 7.8(\mathrm{~s}, 4 \mathrm{H}), 7.7(\mathrm{~s}, 2 \mathrm{H})$, $7.7(\mathrm{~s}, 2 \mathrm{H}), 7.3(\mathrm{~m}, 4 \mathrm{H}), 4.0\left(\mathrm{~m}, 2 \mathrm{H},-\mathrm{OCH}_{2}\right), 2.4(\mathrm{~s}, 6 \mathrm{H})$, $2.35(\mathrm{~m}, 4 \mathrm{H}), 1.6(\mathrm{~m}, 8 \mathrm{H}), 1.5(\mathrm{~m}, 4 \mathrm{H}), 1.4(\mathrm{~m}, 4 \mathrm{H}), 1.2(\mathrm{~m}$, $12 \mathrm{H}) \mathrm{ppm} .{ }^{13} \mathrm{C}-\mathrm{NMR}\left(100 \mathrm{MHz}, \mathrm{CDCl}_{3}\right): \delta=149.4,144.6$, $141.5,133.2,129.8,128.9,127.8,109.6,106.5,92.5,70.6,28.9$, 28.6, 25.3, 21.6, 19.4 ppm. FT-IR (KBr): 3483, 3148, 3109, $3055,2932,2856,1718,1604,1469,1398,1358,1288,1219$, $1176,1099,1024,951,806,777,731,661$. LC-MS analysis $m / z$ : experimental value $=684.6$, calculated value $=683.8$. Anal. Calcd. for $\mathrm{C}_{45} \mathrm{H}_{53} \mathrm{~N}_{5} \mathrm{O}_{6} \mathrm{~S}_{2}$ : C, 65.59; $\mathrm{H}, 6.48 ; \mathrm{N}, 8.50$ found: C, 65.48; H, 6.42; N, 8.61.

2,6-Bis(4-(10-bromodec-1-ynyl)-1H-pyrazol-1-yl)pyridine (5). To the suspended solution of compound $4(0.20 \mathrm{~g}$, $0.242 \mathrm{mmol})$ in dry acetone lithium bromide $(0.0842 \mathrm{~g}$, 
$0.970 \mathrm{mmol}$ ) was added. After $2 \mathrm{~h}$ of stirring at RT, acetone was evaporated under reduced pressure and redispersed in water and crude compound was extracted with DCM. After evaporation of DCM, compound $\mathbf{5}$ was obtained as a white solid (89\% yield). ${ }^{1} \mathrm{H}-\mathrm{NMR}\left(400 \mathrm{MHz}, \mathrm{CDCl}_{3}\right): \delta=$ $8.5(\mathrm{~s}, 2 \mathrm{H}), 7.9(\mathrm{~m}, 1 \mathrm{H}), 7.8(\mathrm{~d}, 2 \mathrm{H}), 7.7(\mathrm{~s}, 2 \mathrm{H}), 3.4(\mathrm{~m}, 2 \mathrm{H}$, $\left.-\mathrm{BrCH}_{2}\right), 2.4(\mathrm{~m}, 4 \mathrm{H}), 1.9(\mathrm{~m}, 4 \mathrm{H}), 1.5(\mathrm{~m}, 4 \mathrm{H}), 1.4(\mathrm{~m}, 8 \mathrm{H})$, $1.3(\mathrm{~m}, 8 \mathrm{H}) \mathrm{ppm} .{ }^{13} \mathrm{C}-\mathrm{NMR}\left(100 \mathrm{MHz} \mathrm{CDCl}_{3}\right): \delta=149.4$, $144.6,141.5,129.0,109.5,106.5,92.5,70.7,34.0,32.7,28.9,28.8$, 26.4, 19.4 ppm. FT-IR (KBr): 3437, 2924, 2854, 1720, 1651, 1599, 1481, 1390, 1101, 1014, 954, 800. LC-MS analysis $m / z$ : experimental value $=502$, calculated value $=501.2$. Anal . Calcd. for $\mathrm{C}_{31} \mathrm{H}_{39} \mathrm{Br}_{2} \mathrm{~N}_{5}$ : C, 58.04; H, 6.13; N, 10.92 found: C, 58.12; H, 6.17; N, 24.87.

$N, N^{\prime}-\left(1,1^{\prime}-\left(10,10^{\prime}-\left(1,1^{\prime}\right.\right.\right.$ - (Pyridine-2,6-diyl)bis(1H-pyrazole-4, 1-diyl))bis(dec-9-yne-10,1-diyl))bis(2-oxo-1,2-dihydropyrimidine-4,1-diyl))diacetamide (1). N4-acetyl cytosine (0.333 g, $1.404 \mathrm{mmol})$ in dry DMF $(15 \mathrm{~mL})$ was taken in $100 \mathrm{~mL}$ round bottom flask. $\mathrm{K}_{2} \mathrm{CO}_{3}(0.258 \mathrm{~g}, 1.814 \mathrm{mmol})$ was added to this solution to convert $\mathrm{N}$-acetyl cytosine into salt. After stirring at room temperature for about $15 \mathrm{~min}$, compound 5 $(0.3 \mathrm{~g}, 0.468 \mathrm{mmol})$ was added and heated to reflux for $16 \mathrm{~h}$ at $80^{\circ} \mathrm{C}$. DMF was removed under reduced pressure and the crude product was redispersed in water and extracted with chloroform. The organic fraction was washed with $0.1 \mathrm{M} \mathrm{HCl}$ $(20 \mathrm{~mL})$ and saturated $\mathrm{NaCl}$ solution $(10 \mathrm{~mL})$. Compound 1 was obtained after evaporation of chloroform in a liquid form and purified by silica gel column chromatography with 5\% methanol/DCM. Pure compound 1 was obtained as a white solid with $55 \%$ yield. ${ }^{1} \mathrm{H}-\mathrm{NMR}\left(400 \mathrm{MHz}, \mathrm{CDCl}_{3}\right): \delta$ $=10.4(\mathrm{~s},-\mathrm{NH}), 8.5(\mathrm{~s}, 2 \mathrm{H}), 7.9(\mathrm{~m}, 1 \mathrm{H}), 7.8(\mathrm{~d}, 2 \mathrm{H}), 7.7(\mathrm{~s}$, $2 \mathrm{H}), 7.6(\mathrm{~d}, 1 \mathrm{H}), 7.4(\mathrm{~d}, 1 \mathrm{H}), 3.8\left(\mathrm{~m}, 2 \mathrm{H},-\mathrm{NCH}_{2}\right), 2.4(\mathrm{~m}$, $4 \mathrm{H}), 2.3$ (s, 6H), $1.7(\mathrm{~m}, 4 \mathrm{H}), 1.5(\mathrm{~m}, 4 \mathrm{H}), 1.4(\mathrm{~m}, 16 \mathrm{H}) \mathrm{ppm}$. ${ }^{13} \mathrm{C}-\mathrm{NMR}\left(100 \mathrm{MHz}, \mathrm{CDCl}_{3}\right): \delta=171.3,162.8,155.7,149.4$, $148.8,144.6,141.5,129.0,109.5,106.9,96.7,92.5,70.6,51.1$, $36.5,31.4,29.7,28.9,26.4,24.8,21.2,19.4$ ppm. FT-IR (KBr): 3325, 3136, 2926, 2852, 1697, 1662, 1556, 1479, 1429, 1381, 1307, 1219, 1178, 1028, 952, 866, 800, 655, 617. LC-MS analysis $m / z$ : experimental value $=646.0$, calculated value $=645.2$. Anal . Calcd. for $\mathrm{C}_{43} \mathrm{H}_{51} \mathrm{~N}_{11} \mathrm{O}_{4}$ : C, 65.71; H, 6.54; N, 19.60 found: C, 65.86; H, 6.51; N, 19.51 .

\subsection{Preparation of Nanovesicles}

Synthesis of Nanovesicles Stabilized by PEG-400. Compound $1(0.5 \mathrm{mg}, 0.00063 \mathrm{mmol})$ was dissolved in $0.5 \mathrm{~mL}$ of DMSO and rapidly injected at vigorous stirring in $50 \mathrm{~mL}$ of deionized water, containing predissolved PEG-400 (0.6 g, $0.0003 \mathrm{mmol}$ ). After 5 minutes of stirring at RT, solution was drop casted on silica and analyzed by TEM, AFM, and micro-Raman spectroscopy. Remaining solution was left at moderate stirring at RT for $120 \mathrm{~h}$, and sample was collected and analyzed every $24 \mathrm{~h}$.

Synthesis of Nanovesicles Stabilized by PEG-2000. The experiment was performed as described above; PEG-2000 was used instead of PEG-400.
Synthesis of TFN-Loaded Stabilized Nanovesicles. Stock solution of terfenadine (TFN) was prepared by dissolving $2 \mathrm{mg}$ of TFN in $1 \mathrm{~mL}$ of deionized water. $1(0.5 \mathrm{mg}, 0.00063 \mathrm{mmol})$ was dissolved in $0.45 \mathrm{~mL}$ of DMSO, mixed with $0.05 \mathrm{~mL}$ of TFN stock solution, and rapidly injected at vigorous stirring in $50 \mathrm{~mL}$ of deionized water, containing predissolved PEG-2000 (0.6 g, $0.0003 \mathrm{mmol})$. After $12 \mathrm{~h}$ of stirring at RT solution was filtered through syringe with hydrophilic syringe filter (Millipore, pores size $0.45 \mu \mathrm{m}$, hydrophilic, PVDF) to remove an excess of TFN and PEG-2000 and then vesicles were washed with deionized water and final volume was adjusted to $10 \mathrm{~mL}$ (solution V1-TFN). This solution was used to identify concentration of TFN in vesicles, stability of drugloaded vesicles and for zebrafish studies. See also schematic representation of the experiments (Figures 2 and 3).

2.3. Characterization of Nanovesicles. Size and morphology of the nanostructures were examined by scanning electron microscope (SEM), atomic force microscopy (AFM), and transmission electron microscope (TEM). SEM studies were performed using a Philips XL30 ESEM scanning electron microscope with a beam voltage of $20 \mathrm{kV}$. FESEM measurements were performed on a Hitachi S-4500 SE/N instrument operating at $20 \mathrm{kV}$. TEM studies were done using Tecnai G2 FEI F12 transmission electron microscope (TEM) at an accelerating voltage of $200 \mathrm{kV}$. Carbon coated TEM grids (200 mesh type-B) were purchased from TED PELLA INC. USA. Atomic force microscopy (AFM) imaging was carried out on NT-MDT model solver Pro $\mathrm{M}$ microscope using a class $2 \mathrm{R}$ laser of $650 \mathrm{~nm}$ wavelength having maximum output of $1 \mathrm{~mW}$. All calculations and image processing were carried out by a software NOVA 1.0 .26 .1443 provided by the manufacturer. The images were recorded in a semicontact mode using a noncontact super sharp silicon cantilever (NSG 10_DLC) diamond like carbon (DLC) tip purchased from NT-MDT, Moscow. The dimension of the tip is as follows: cantilever length $=100( \pm 5) \mu \mathrm{m}$, cantilever width $35( \pm 5) \mu \mathrm{m}$, and cantilever thickness $=1.7-2.3 \mu \mathrm{m}$; resonate frequency $=$ $190-325 \mathrm{kHz}$; force constant $=5.5-22.5 \mathrm{~N} / \mathrm{m}$; chip size $=3.6 \times$ $1.6 \times 0.4 \mathrm{~mm}$; reflective side $=\mathrm{Au}$; tip height $=10-20 \mu \mathrm{m} ; \mathrm{DLC}$ tip curvature radius $=1-3 \mathrm{~nm}$.

AFM, LCFM, SEM, FESEM, and TEM-Samples Preparation. Two drops of the sample solution were drop casted on a clean glass slide by a capillary for AFM studies. Two drops of the sample solution were drop casted on a carbon coated copper grid (200 Mesh) with different time intervals for TEM studies of nanostructures.

Stability of Drug-Loaded Vesicles Study. Solution V1-TFN was left at moderate stirring at RT for $120 \mathrm{~h}$, and sample was collected and analyzed every $24 \mathrm{~h}$ to identify time point when nanovesicles disintegration will begin.

Determination of Concentrations of TFN in Surrounding Media (Figure 3). TFN concentration in solution resulting from leakage from the nanovesicles was investigated at different time points following procedure described below: $1 \mathrm{~mL}$ of solution V1-TFN was collected, filtered through hydrophilic 


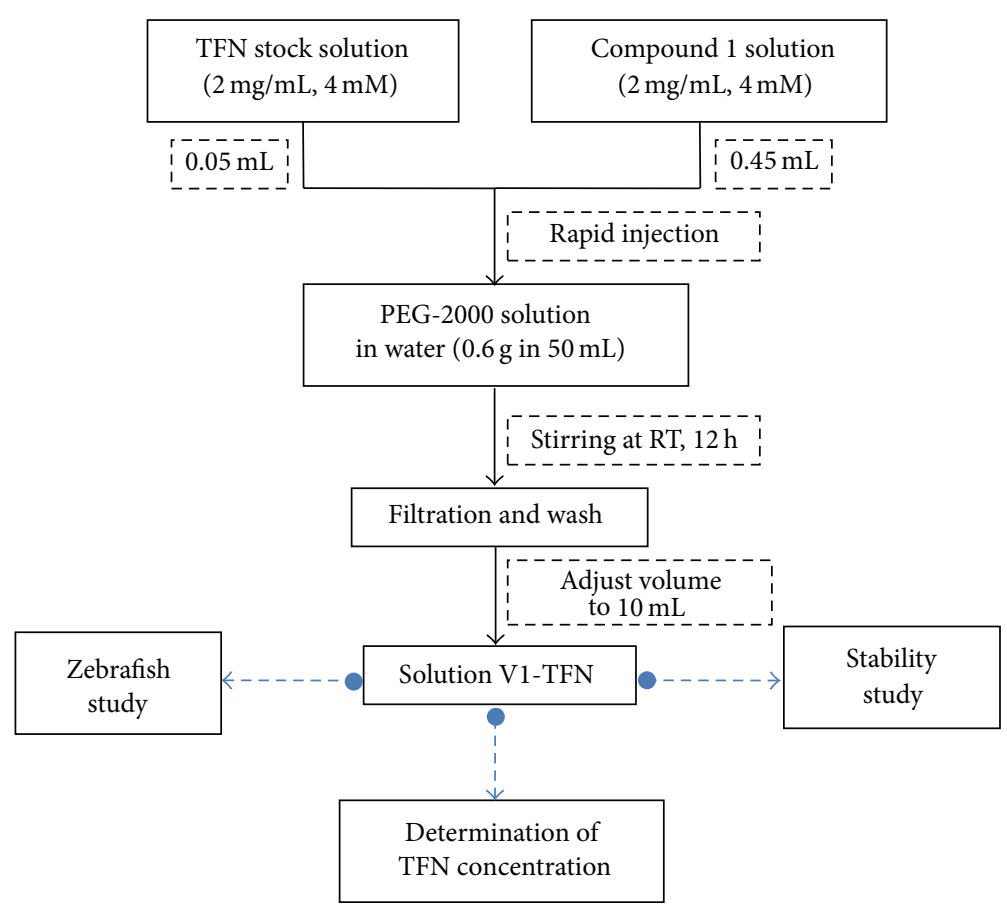

FIGURE 2: Schematic representation of TFN-loaded nanovesicles preparation.

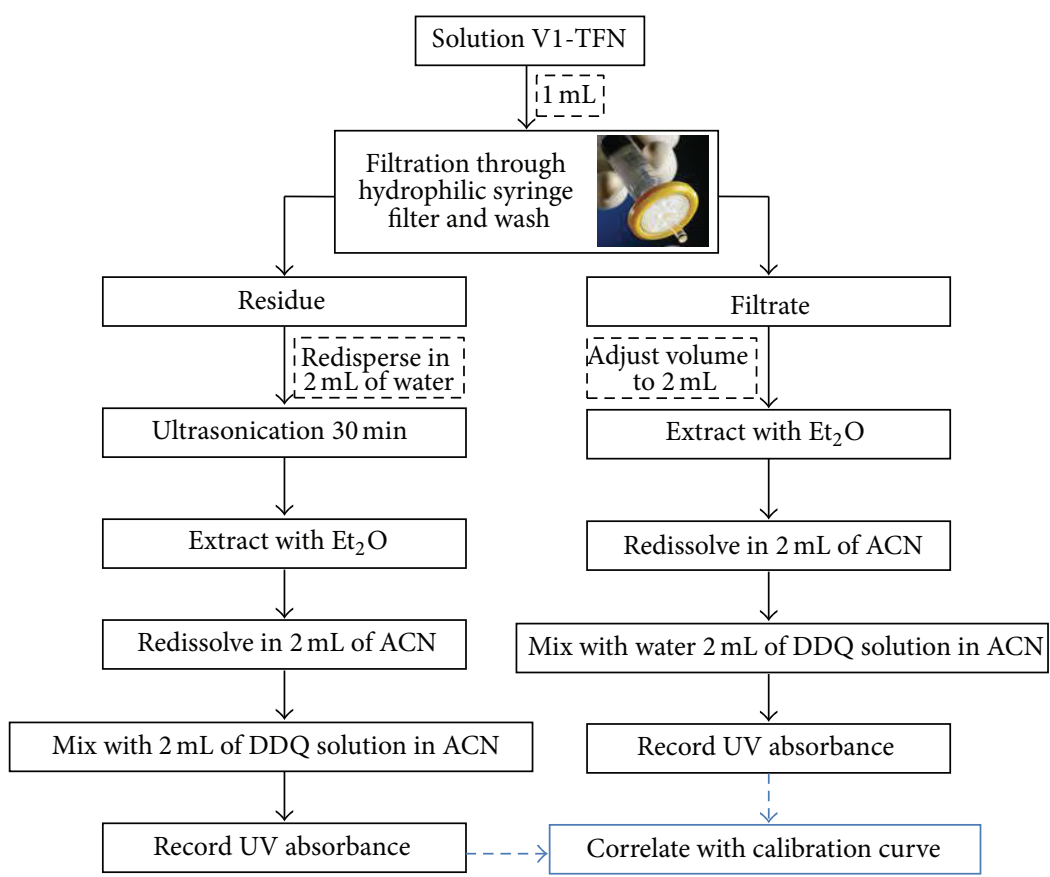

FIGURE 3: Determination of TFN concentration inside vesicles and in surrounding media (repeated at different time points).

syringe filter, and washed 1 time with $1 \mathrm{~mL}$ of deionized water. TFN was extracted from filtrate with diisopropyl ether; solvent was evaporated and remaining TFN was redissolved in $2 \mathrm{~mL}$ of acetonitrile. Concentration of TFN in this solution was measured according to modified published procedure
$[15,16]$. TFN solution in acetonitrile $(2 \mathrm{~mL})$ was mixed with $2 \mathrm{~mL}$ of DDQ solution $(5 \mathrm{mg} / \mathrm{mL})$. The colored species were generated and absorbance intensity was measured immediately at $457 \mathrm{~nm}$ and compared with calibration graphs, which were constructed by plotting the absorbance of the formed 
CT complexes versus the final concentration of the drug $(\mu \mathrm{g} / \mathrm{mL})$. This study was repeated for the samples collected every $24 \mathrm{~h}$ up to $120 \mathrm{~h}$.

Determination of Concentrations of TFN inside Nanovesicles (Figure 3). Concentrations of TFN inside vesicles at different time points were investigated following procedure described below: $1 \mathrm{~mL}$ of solution V1-TFN was collected, filtered through hydrophilic syringe filter, and washed 1 time with $1 \mathrm{~mL}$ of deionized water to remove excess of the drug and PEG-2000, and residue was redispersed in $2 \mathrm{~mL}$ of water and subjected to sonication for $30 \mathrm{~min}$ at RT to break down all vesicles and release TFN. The ability of ultrasound to induce localized and controlled drug release from liposomes, synthetic diblock copolymers, and polymersomes is well known phenomena $[17,18]$. Next, TFN was extracted from this solution with large volume of diisopropyl ether; solvent was evaporated and remaining TFN was redissolved in $2 \mathrm{~mL}$ of acetonitrile. Replacement of solvent with $\mathrm{ACN}$ was necessary because it showed super priority over other solvents for the formation of CT complex, at the same time facilitating charge-transfer from donor to acceptor. Absorbance intensity of TFN solution in ACN was then measured at selected absorption maximum $(457 \mathrm{~nm})$ and obtained value was compared with values of calibration curve obtained using solutions of TFN:DDQ complex of known concentrations (see also Figures 9 and 10). The concentration of TFN calculated applying Beer-Lambert law was $37.5 \mu \mathrm{M}$, which allowed us to find out drug loading efficiency using the following equation:

$$
\text { Loading Efficiency }=\frac{C_{1}}{C_{0}} \times 100 \% \text {, }
$$

where $C_{0}$ is an initial concentration of TFN in solution, whereas $C_{1}$ is concentration of TFN in vesicles after loading. This study was repeated for the samples collected every $24 \mathrm{~h}$ up to $120 \mathrm{~h}$.

\subsection{Zebrafish Studies}

Zebrafish Teratogenicity Assessment. Zebrafish maintenance, breeding, and embryo collection was carried out by methods described previously $[19,20]$. Briefly, wild-type adult zebrafish (5-6 months old) were maintained at $28^{\circ} \mathrm{C}$ under a $14: 10 \mathrm{~h}$ light and dark cycle. Fish were allowed to breed (in a ratio of 2 females: 3 males) in the morning under the stimulation of light. Embryos were collected into petridish containing embryo medium and incubated at $28^{\circ} \mathrm{C}$ temperature. The teratogenicity study was performed using 6 embryos that were incubated with vehicle, positive control, and various concentrations of test compound $\mathbf{1}$ until $\mathbf{5} \mathrm{dpf}$. The embryos were then anesthetized using $0.008 \%$ tricaine solution and various phenotypic parameters were evaluated; namely, body shape, somites, notochord, tail, intestine, fins, brain, upper jaw, heart, lower jaw, liver, and swim bladder were observed for defects in morphology [21]. Each embryo was scored based on their level of toxicity from 5 being nontoxic and 0.5 being highly toxic. The scoring was conducted by
TABLE 1: Results of zebrafish embryo toxicity study with toxicological indices and major organs/systems affected in positive control and at MTC in test compounds (-: no effect, $\mathbf{x}$ : slightly toxic, $\mathbf{x x}$ : moderately toxic, and $\mathbf{x x x}$ : severely toxic).

\begin{tabular}{lcc}
\hline & $\begin{array}{c}\text { Tested } \\
\text { compound }(\mathbf{1})\end{array}$ & Phenobarbital \\
\hline Test concentrations $(\mu \mathrm{M})$ & $0.03,0.1,0.3,1$, & 3000 \\
Statistically significant toxic & $3,10,30$ & \\
concentration $(\mu \mathrm{M})$ & - & Positive \\
No observed adverse & & Control \\
effect level (NOAEL) $(\mu \mathrm{M})$ & $\mathbf{3 0}$ & \\
Minimal toxic & & \\
concentration $(\mathrm{MTC})(\mu \mathrm{M})$ & - & \\
Parameters of toxicity at & & \\
MTC & & \\
Body shape & $\mathbf{x}$ & $\mathbf{x x \mathbf { x }}$ \\
Somites & - & $\mathbf{x x x}$ \\
Notochord & - & $\mathbf{x x x}$ \\
Tail & - & $\mathbf{x x x}$ \\
Fins & - & $\mathbf{x x x}$ \\
Brain & - & $\mathbf{x x x}$ \\
Upper jaw & - & $\mathbf{x x x}$ \\
Heart & - & $\mathbf{x x}$ \\
Intestine & $\mathbf{x}$ & $\mathbf{x x x}$ \\
Lower jaw & - & $\mathbf{x x x}$ \\
Liver & - & $\mathbf{x x x}$ \\
Swim bladder & & \\
\hline
\end{tabular}

blinded observers and was done according to the procedures described earlier [22].

Protocol for Zebrafish Treatment with TFN-Loaded Nanovesicles. For TFN-NV assessment, $3 \mathrm{dpf}$ (days post fertilization) larvae were distributed in 24-well plate along with $250 \mu \mathrm{L}$ of $0.1 \%$ DMSO solution. Each well contained 6 embryos with various treatments and the larvae were observed at time points of $24 \mathrm{~h}, 48 \mathrm{~h}$, and $72 \mathrm{~h}$. Embryos were then treated with different concentrations of TFN loaded microvesicles $(5 \mu \mathrm{M}, 10 \mu \mathrm{M}, 20 \mu \mathrm{M}$, and $40 \mu \mathrm{M})$. TFN alone at $20 \mu \mathrm{M}$ concentration was used as a positive control and 0.1\% DMSO was used as a negative control. The embryos were incubated in 24-well plate and atrial and ventricular rates were observed at different time points after treatment. All embryos were observed for mortality arising out of effect of TFN. Results of zebrafish embryo toxicity study are summarized in Table 1.

\section{Results and Discussion}

3.1. Synthesis and Characterization of Compound 1. Molecule 1 was synthesized in six steps from BPP (Scheme 1). Iodination of the $4,4^{\prime \prime}$-positions of the BPP to synthesize 2 was carried out as per our reported procedure $[13,14]$. Attachment of "linker molecule" decyn-1-ol to 2 was achieved by adopting Sonogashira cross-coupling conditions to get $\mathbf{3}$ in good 


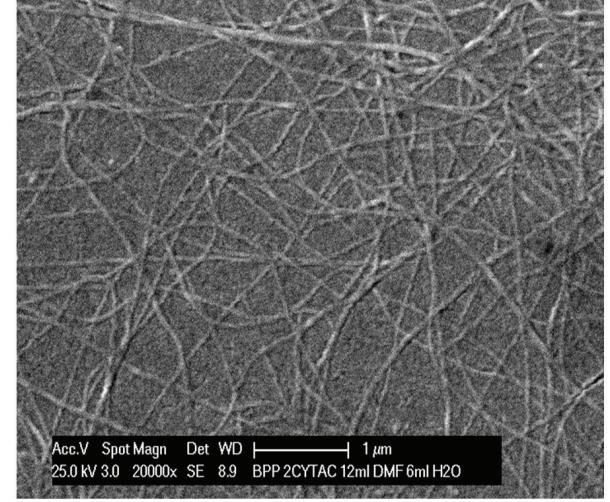

FIGURE 4: SEM micrographs of nanofibrous network assemblies formed from compound $\mathbf{1}$ in DMF/water.

yields (80\%). Compound 3 was tosylated in DCM solvent in presence of triethyl amine as base to give 4 in $75 \%$ yield. Compound 5 was prepared in excellent yield (89\%), upon treatment of $\mathbf{4}$ with $\mathrm{LiBr}$ in acetone at room temperature. The target bolaamphiphile 1 containing water soluble end groups connected to a hydrophobic alkyl chains was obtained in 55\% yield, by treating 5 with N4-acetyl cytosine in presence of potassium carbonate at $80^{\circ} \mathrm{C}$. Variable temperature ${ }^{1} \mathrm{H}-\mathrm{NMR}$ studies of 1 in $\mathrm{CDCl}_{3}$ showed a clear down field chemical shift of the cytosine - $\mathrm{NH}$ - group upon decreasing the temperature (Supplemental Information Figure S1 available online at http://dx.doi.org/10.1155/2014/369139). This observation indicates the operating intermolecular $\mathrm{H}$ bonding interaction of the cytosine. Furthermore, slow addition of water to the DMF solution $\left(10^{-3} \mathrm{M}\right)$ of $\mathbf{1}$ showed a clear blue shift during UV titration indicating its J-aggregation behaviour.

3.2. Investigation of Nanostructures Formation. To study the aggregation driven nanostructure formation, a solution containing $2 \mathrm{mg}$ of compound $\mathbf{1}$ in DMF $(12 \mathrm{~mL}) /$ water $(6 \mathrm{~mL})$ was prepared and stabilized for an hour. Drop casting this solution on silica followed by SEM analysis showed the formation of clear fibrous networks of several microns long (Figure 4). To unravel the mechanism of formation of nanofibrous network assemblies, the same solution of 1 was drop casted immediately without stabilization on a carbon coated TEM grid. Interestingly, the TEM micrographs showed the presence of tiny vesicles of size in the range of $200 \mathrm{~nm}$ (Figure 5(a)) and some aggregated pearl-chain linked vesicles of size in the range of $\sim 150 \mathrm{~nm}$ (Figure 5(b)). Additionally the generation of $1 \mathrm{D}$ pearl chain-like assembly by the fusion of vesicles indicates the formation of nanotubular network (Figures 5(c) and 5(d)). To further verify the fusion of spherical vesicles into nanotubes on silica surface AFM studies were undertaken. The AFM topography clearly revealed the presence of nanovesicles (NVs) of sizes $\sim 200 \mathrm{~nm}$ (Figures 6(a) and 6(b)). Interestingly, some of the samples showed spontaneous formation of pearl-chain like vesicular assemblies or nanotube integrated vesicles, pointing out to vesicles fusion. For every $1 \mu \mathrm{m}$ chain length ca. 5 fused vesicles were found, which is matching with the average diameter of the vesicles (Figures 6(c) and 6(d)). Continuous AFM measurement revealed the evolution of smooth nanotubular structures of diameter $\sim 160 \mathrm{~nm}$ from the pearl-chain like vesicular assemblies due to the molecular reorganization (Figures 6(e) and 6(f)). The finally formed tubes diameter $(\sim 160 \mathrm{~nm})$ is less than the initial vesicle diameter of a single isolated vesicle $(\sim 200 \mathrm{~nm})$ due to the stretching of the fused vesicles during the $1 \mathrm{D}$ tube formation. The diameter of the tube is determined by the balance between surface tension and tube bending rigidity, preventing membrane collapse. The outer surface of the tubes is very smooth with a roughness smaller than $<1 \mathrm{~nm}$ (Figures $6(\mathrm{~g})$ and $6(\mathrm{~h})$ ). This result demonstrated the flexible nature of the presented synthetic membrane composed of $\mathbf{1}$. Another interesting finding of the nanotubes is their tendency to form various types of networkjunctions through self-organization (Figure 6(e), insert).

3.3. Control over Nanostructure Using Stabilizing Agents. To demonstrate application of NVs for drug delivery, in the first step, different conditions were screened to stabilize vesicles in solution state and prevent formation of tubular structures. We intended to use polyethylene glycol (PEG) as stabilizing agent since it is biologically neutral and furthermore FDAapproved biocompatible polymer well suitable for pharmaceutical applications [23]. PEG-400 and PEG-2000 were employed for stabilization of nanovesicles. In a typical procedure a DMSO solution of compound $\mathbf{1}(0.5 \mathrm{mg}$ in $0.5 \mathrm{~mL})$ was rapidly injected into a deionized water containing PEG $(0.6 \mathrm{~g}$ in $50 \mathrm{~mL}$ ) under vigorous stirring for 5 minutes at RT. NVs PEGylated with polymer of lower molecular weight (PEG400) did not demonstrate high stability; however the use of PEG-2000 stabilized the vesicles up to $108 \mathrm{~h}$. Even at that time point a significant amount of vesicles retained their structure, although their surface was not as smooth as it was at 24 and 48 hours. The size distribution of the NVs was in the range of $<60 \mathrm{~nm}$ to $130 \mathrm{~nm}$; an insignificant amount of bigger vesicles $(\sim 250 \mathrm{~nm})$ was also observed (Figures 7(a) and 7(b)).

3.4. Toxicity Investigation of Stabilized Nanovesicles Using Zebrafish Teratogenicity Assay. For NVs based drug delivery studies, zebrafish was selected as a model organism since it is easy to maintain, is relatively inexpensive, gives quick results and, is a good predictor of efficacy and safety of chemicals $[24,25]$. In order to explore toxicity of compound 1 zebrafish teratogenicity assay was performed. Treatment of $24 \mathrm{hpf}$ (hours after fertilization) embryos with solution of 1 at different concentrations and study of their growth and development for 5 days show no abnormalities (Figure 8 and Table 1). Figure 5 represents mean lesion score of all parameters different treatment groups. This experiment confirmed the nontoxic nature of $\mathbf{1}$ at all tested concentrations.

3.5. Terfenadine Loading into Nanovesicles. For drug delivery study, a well-known antihistamine drug terfenadine (TFN) was selected as a model drug. TFN is also known to affect heartbeat regularity in zebrafish, leading to bradycardia, atrioventricular blockage and ultimately death in less than $12 \mathrm{~h}$ [26]. Selection of this drug facilitates easy monitoring of 


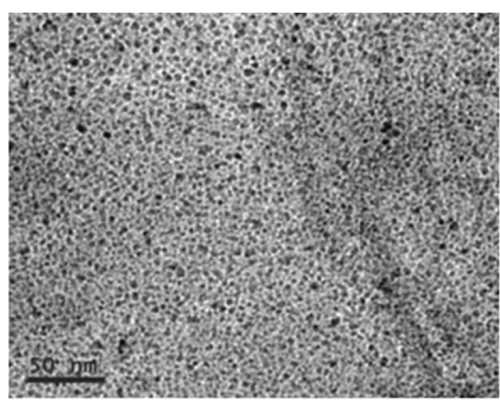

(a)

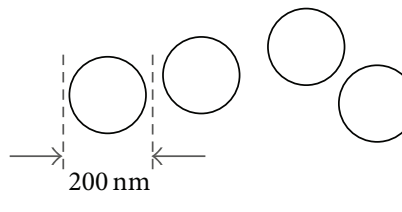

Random vesicles

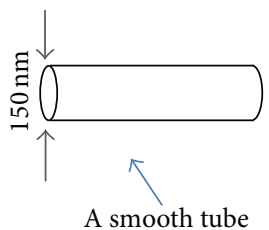

VI

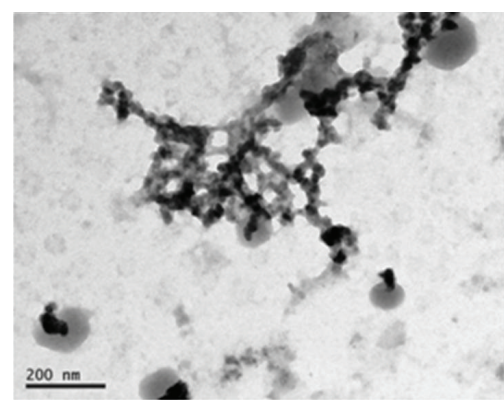

(b)

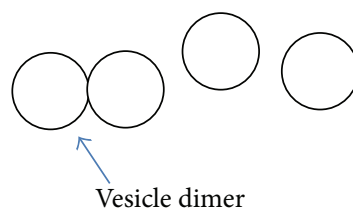

II

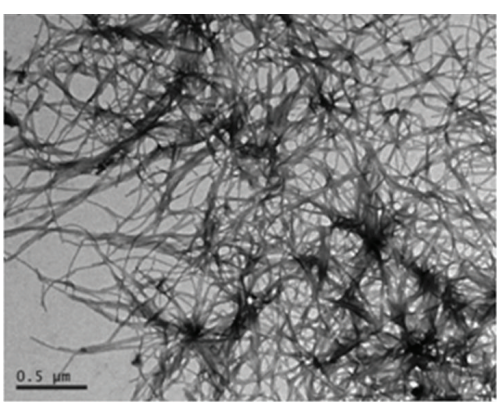

(c)

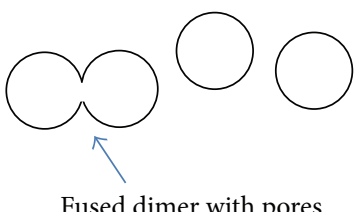

Fused dimer with pores

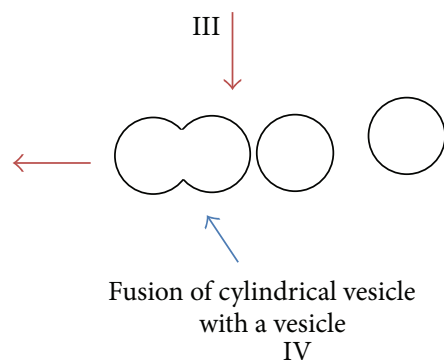

(d)

FIGURE 5: TEM micrographs of nanostructures obtained from compound 1 in DMF/water mixture: (a) distribution of nanovesicles; (b) pearlchain like fused nanovesicles; (c) nanotubes; (d) proposed mechanism of nanotube formation by vesicle fusion.

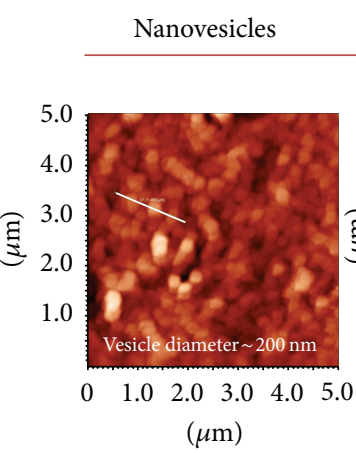

(a)

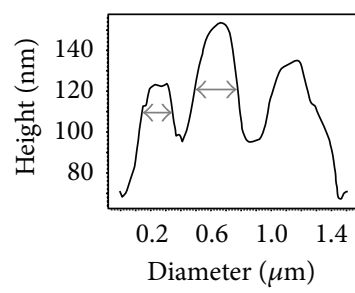

(b)

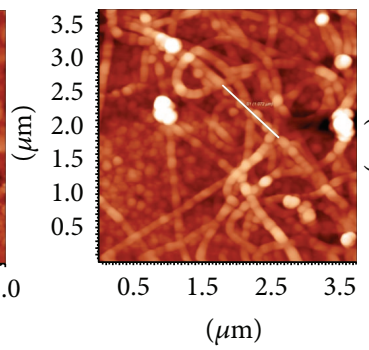

(c)

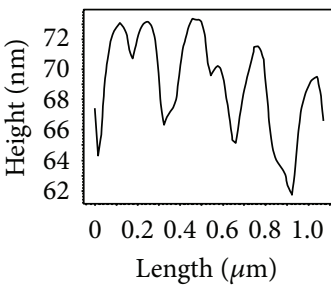

(d)

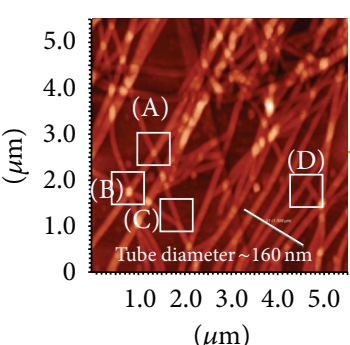

(e)

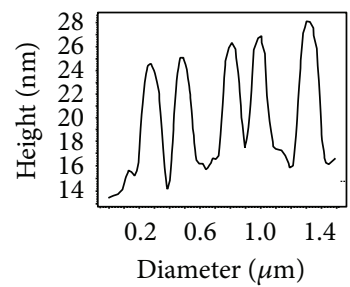

(f)
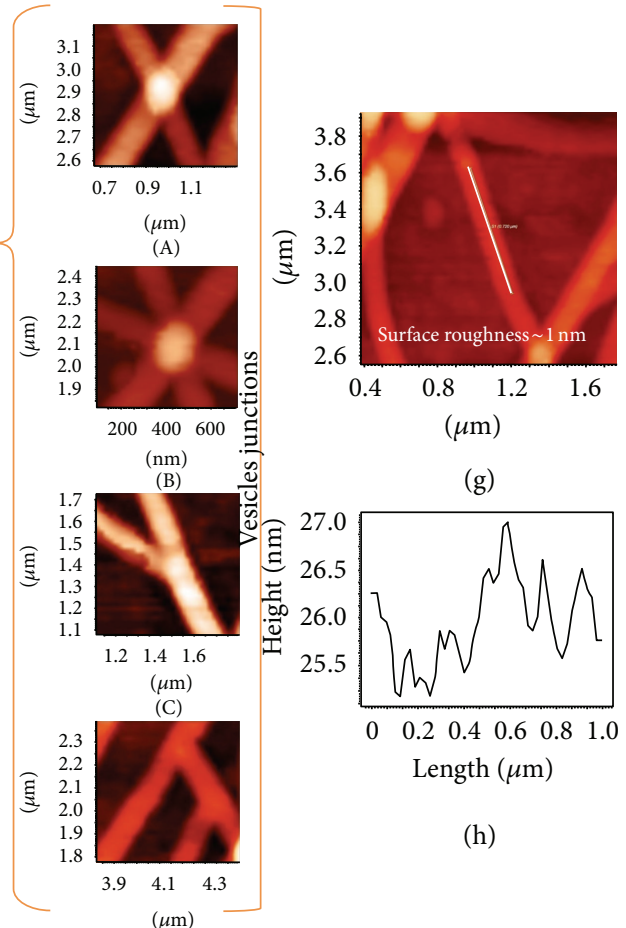

(h)

(D)

FIGURE 6: AFM mechanistic analysis of the formation of nanotubes from nanovesicles: (a) randomly distributed vesicles, (c) fusion of vesicles to form pearl-chain like structures, (e) nanotubes, and (g) roughness of a tube. The corresponding profile analyses are shown in (b), (d), (f), and (h), respectively. 


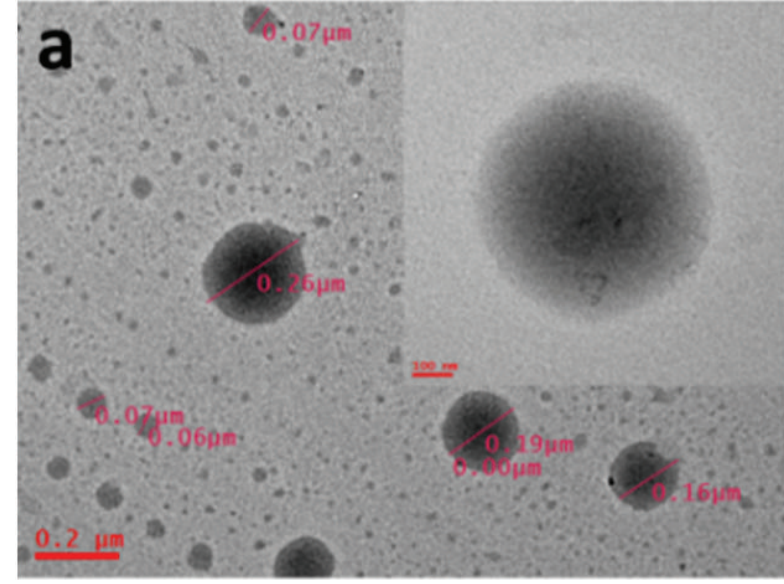

(a)

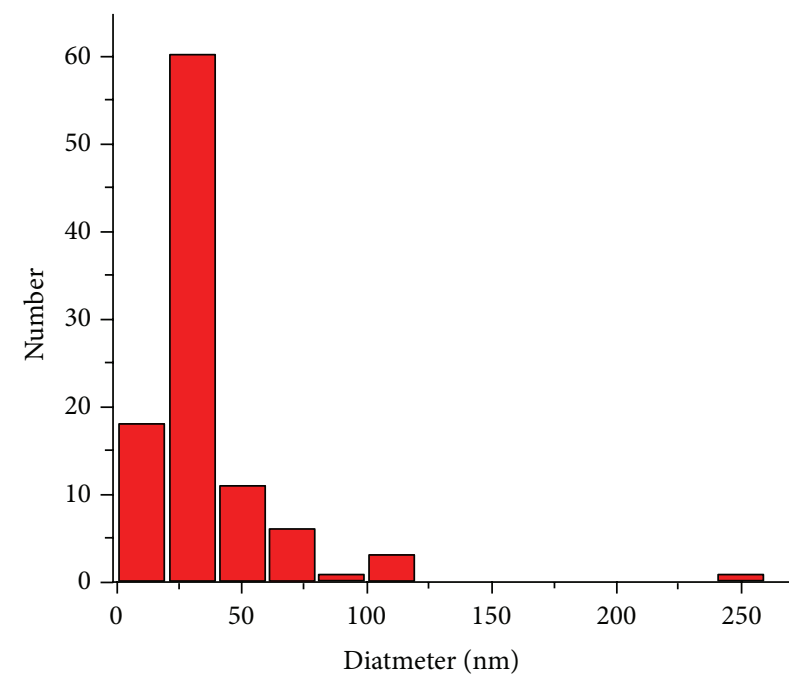

(b)

FIGURE 7: (a) TEM micrograph image of nanovesicles stabilized by PEG-2000; (b) size distribution histogram obtained for stabilized nanovesicles.

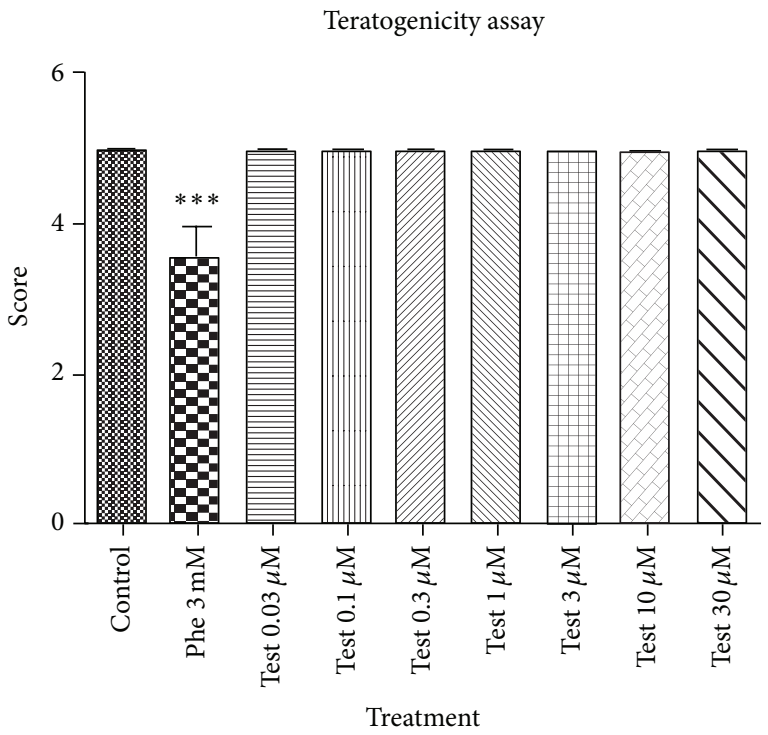

FIgURE 8: Mean ( \pm S.D.) lesion score of all parameters different treatment groups. $\left({ }^{*} P<0.05,{ }^{* *} P<0.01\right.$ and ${ }^{* * *} P<0.001$.) Statistical significance was analyzed as control group versus all groups.

its effect on zebrafish by observing the endpoint of mortality at different time points after treatment. As the nontoxic nature of $\mathbf{1}$ in the zebrafish teratogenicity assay is already tested, any mortality of zebrafish is only attributable to the effect of TFN. Additionally, this procedure is simple, rapid, and noninvasive method of detection of drug action. To prepare drug-encapsulated nanovesicles, TFN and compound 1 were dissolved in DMSO and rapidly injected in solution of PEG-2000 in water with vigorous stirring. The drugencapsulated nanovesicles solution was left for $12 \mathrm{~h}$ for ageing, resultant solution was subsecuently subjected to study the TFN-loading efficiency and nanovesicles stability.

Determination of TFN concentration in biological samples is a challenging analytical task. Straightforward application of spectroscopic methods (for instance, measuring intensity of UV absorption and fluorescent emission) is not applicable as there is no correlation between obtained values and drug content. The majority of current reported methods (e.g., HPLC or NMR) lack sensitivity to measure the drug level at concentrations below $10 \mu \mathrm{g} / \mathrm{mL}[15,16]$. Hence spectrophotometric determination method based on the charge-transfer (CT) reactions of TFN with 2,3-dichloro5,6-dicyano-1,4-benzoquinone (DDQ) was opted [15]. This technique is one of the most simple, rapid, and accurate methodologies developed till now. In this method, TFN acts as n-electron donor which forms a highly colored charge transfer (CT) complex upon spontaneous reaction with strong $\pi$-acceptor DDQ. In order to implement this procedure and find out initial concentration of the drug loaded in vesicles, we have developed an in-house protocol (Figures 3, 9, and 10). Using this method, the calculated drug loading efficiency into the vesicles was $\sim 35 \pm 1 \%$. Further, in order to prove that there is no drug leakage from vesicles into surrounding media over time, we performed stability control experiment: drug-loaded vesicles were gently stirred at RT up to $120 \mathrm{~h}$, collecting sample every $24 \mathrm{~h}$ and detecting concentration of TFN inside vesicles and in mother liquid (solution collected prior to sonication) at every time-point as described in Figure 3. The experiment revealed that there is no major leakage observed up to $72 \mathrm{~h}$ (Figure 11) and concentration of TFN in media remains below $10 \mu \mathrm{M}$, which is zebrafish sensitivity threshold (fish development and heartbeat are not affected below this concentration of TFN). Subsequently, drug burst release was observed after $72 \mathrm{~h}$, when TFN concentration in mother liquid suddenly increased and crossed $10 \mu \mathrm{M}$. Simultaneously, TFN concentration inside 


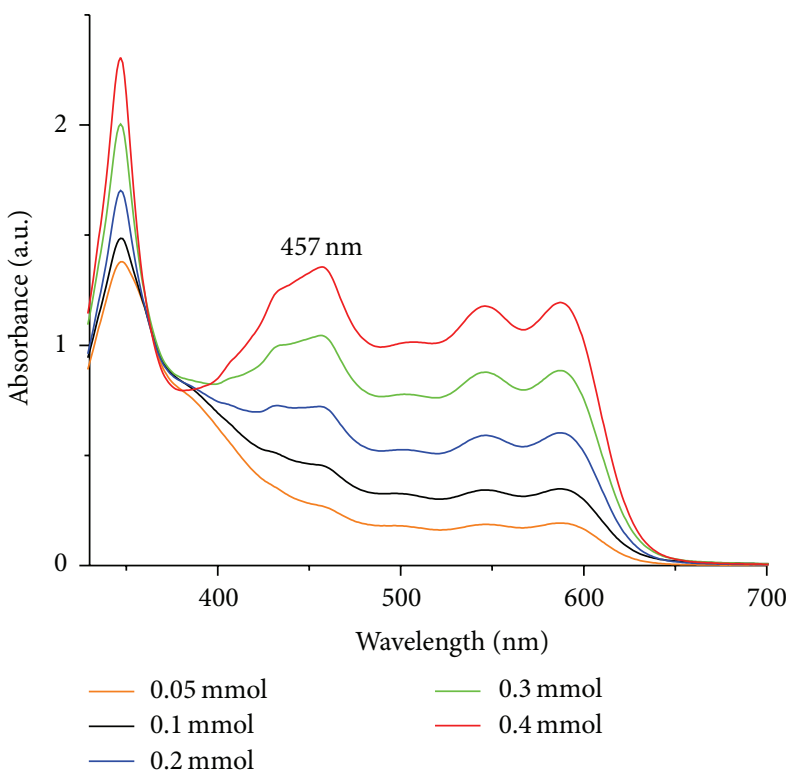

(a)

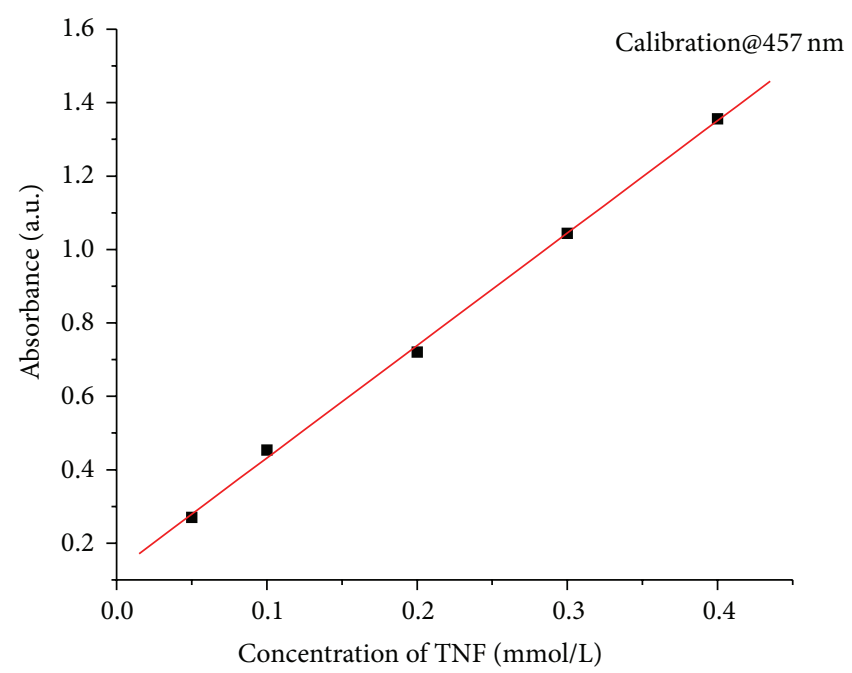

(b)

FIGURE 9: (a) Absorbance of TFN at different concentrations in acetonitrile as complex with DDQ (DDQ concentration was maintained constant: $22 \mathrm{mM}$ for all samples) and (b) calibration graphs derived from (a) according to Beer-Lambert law.

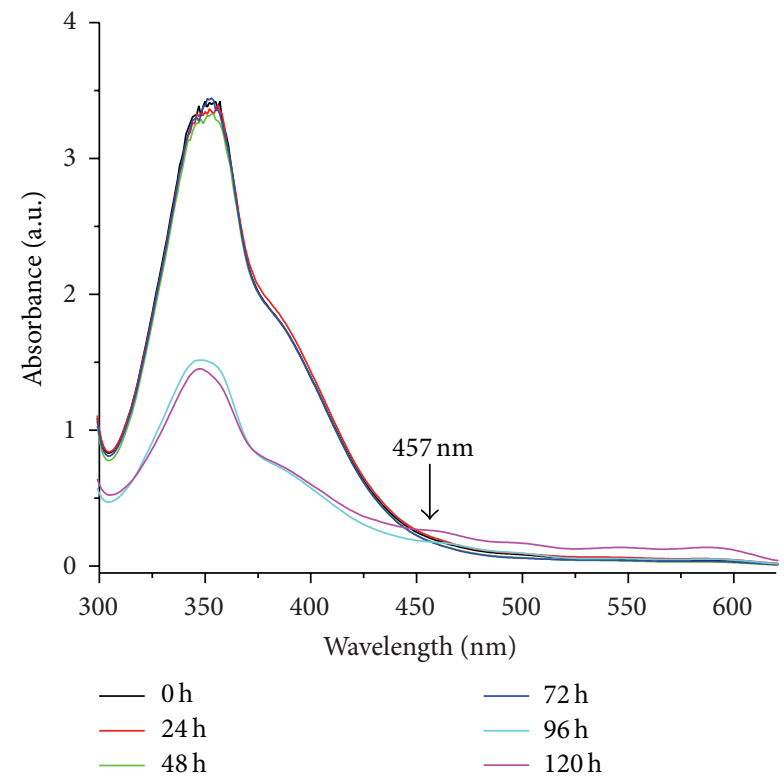

Figure 10: Absorbance of TFN:DDQ complex in acetonitrile at different time points (to determine concentration, the value of absorbance intensity at $457 \mathrm{~nm}$ was recorded and compared with value in calibration curve).

NVs decreased dramatically after $72 \mathrm{~h}$. We assumed that slow dissolution of PEG coating resulted in deformation of NVs and sudden drug release (Figure 6, cartoon). These data correlate well with TEM data recorded for vesicles at different time points. Figures 12 (a) and 12(b) represent TEM images of the vesicles at 24 and $72 \mathrm{~h}$, respectively. At $24 \mathrm{~h} \mathrm{NVs}$ have

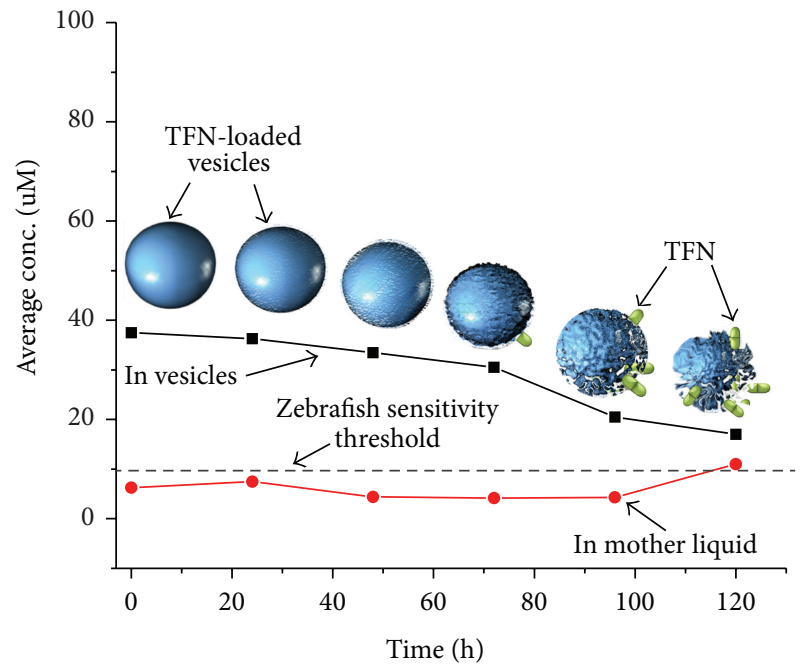

FIGURE 11: TFN concentration change inside vesicles and in mother liquid at different time points. Cartoon represents slow deformation of vesicles and TFN "burst" drug release after $72 \mathrm{~h}$.

well-structured defined shape (Figure 12(a)), while at $72 \mathrm{~h}$ we observe degradation of NVs and decrease of NVs amount (Figure 12(b)). This explains well drug burst release after $72 \mathrm{~h}$, an effect commonly seen in case of nano-/microsphere or nano-/microvesicles systems $[27,28]$.

3.6. Sustained Drug Delivery of TFN-Loaded Nanovesicles in Zebrafish Larvae. Zebrafish larvae were treated with TFNloaded nanovesicles (TFN-NV) at four different concentrations $(5 \mu \mathrm{M}, 10 \mu \mathrm{M}, 20 \mu \mathrm{M}$, and $40 \mu \mathrm{M}$ of $\mathrm{TFN})$ and 


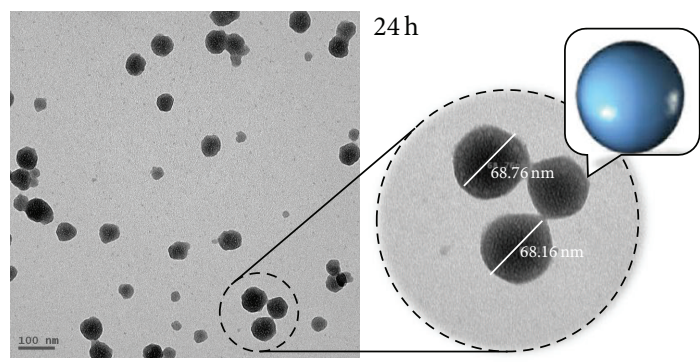

(a)

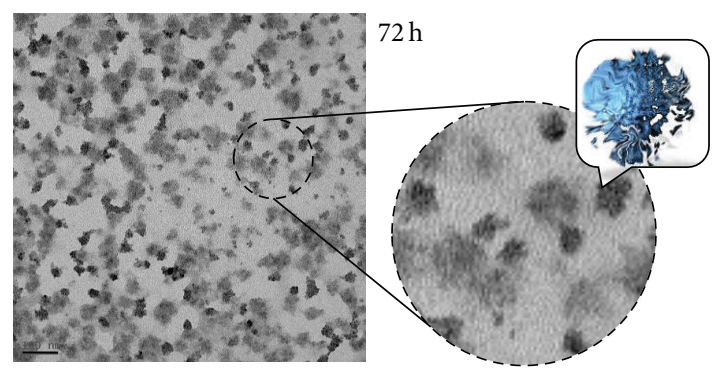

(b)

FIGURE 12: TEM micrograph images of TFN-loaded nanovesicles (a) at $24 \mathrm{~h}$; scale bar is $100 \mathrm{~nm}$; (b) at $72 \mathrm{~h}$; scale bar is $100 \mathrm{~nm}$; cartoon shows vesicles deformation over time.

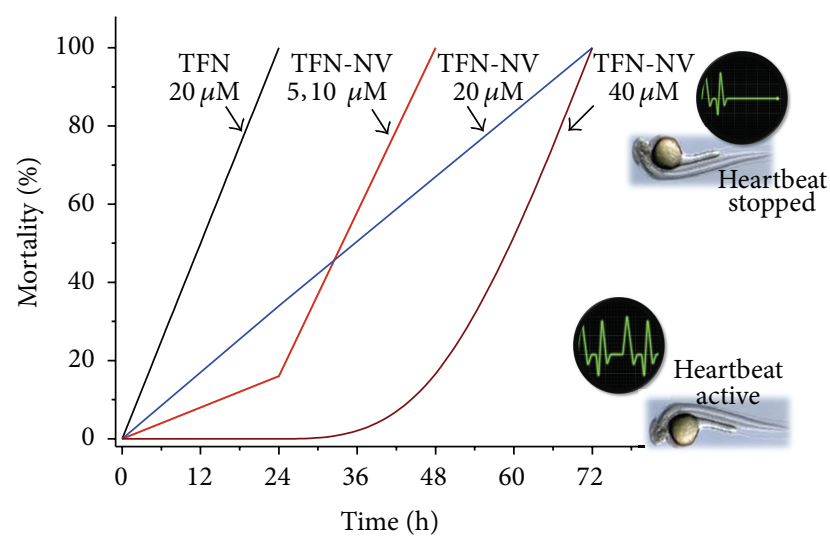

Figure 13: Percentage mortality in zebrafish larvae exposed to various concentrations of TFN-loaded nanovesicles (TFN-NV) at different time points.

were observed at the time points of $24 \mathrm{~h}, 48 \mathrm{~h}$, and $72 \mathrm{~h}$ to investigate mortality caused by TFN after drug treatment (Figure 13). TFN alone at a concentration of $20 \mu \mathrm{M}$ was used as positive control. The observations showed that all larvae in positive control (TFN alone, $20 \mu \mathrm{M}$ ) died within $12 \mathrm{~h}$. For larvae exposed to TFN-NV at low concentrations (5$10 \mu \mathrm{M}$ ) first cases of mortality (and therefore drug effect) were observed at $24 \mathrm{~h}$ and all fish died within 48 hours. Still further prolongated effect was observed at $20 \mu \mathrm{M}$; mortality was slowly increasing starting from $24 \mathrm{~h}$ and complete mortality detected only by $72 \mathrm{~h}$.

No cases of death were observed for larvae treated with the highest drug concentration up to $48 \mathrm{~h}$, but all of them were dead at $72 \mathrm{~h}$ time point. The explanation of this aberration at highest concentration can be based on the fact that the TFN-NV at $40 \mu \mathrm{M}$ form aggregates (Figure 14) and therefore might not enter the systemic circulation in the larval zebrafish; however by 72 hours TFN-NV would release all TFN causing late mortality. Vesicles stability study and TEM data (Figures 11, 12, and 14) support this explanation. Apart from that, we observed precipitation of nanovesicles from $40 \mu \mathrm{M}$ solution if left undisturbed. The delayed mortality seen in other concentrations is suggestive of a sustained/delayed release of TFN from TFN-NV in vivo, which can be controlled by changing concentration of nanovesicles. As we did

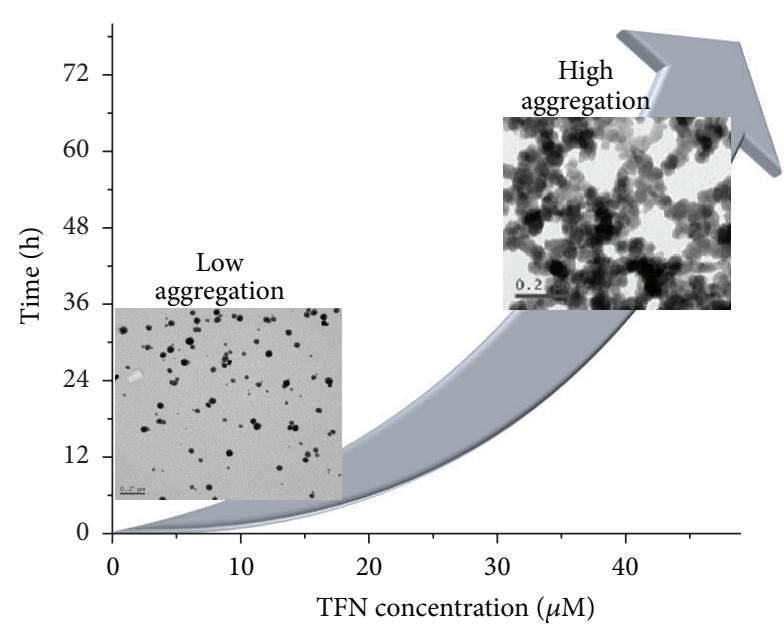

FIGURE 14: Graphical representation of increased aggregation and therefore slow drug release depending on time and TFN concentration. Inserts show TEM micrographs of TFN-loaded nanovesicles; scale bar is $0.2 \mu \mathrm{M}$.

not observe major leakage of the drug from nanovesicles up to $72 \mathrm{~h}$ (the concentration of the drug in mother liquid was below zebrafish sensitivity threshold), we conclude that effect of TFN below $72 \mathrm{~h}$ is observed only after the drug is released inside zebrafish organism.

\section{Conclusion}

Nontoxic and polymer stabilized organic nanovesicles as drug delivery cargoes are prepared from a novel bioinspired 2,6-bispyrazolylpyridine derivative decorated with cytosine moieties. Spontaneous self-assembly of nanovesicles into "pearl-like" chains and subsequent fusion into nanotubes are investigated and protocol is developed to prevent pearling by protecting nanovesicles with biocompatible PEG-2000. Further the vesicles are loaded with terfenadine drug and successfully utilized to transport into zebrafish larvae and release the drug in sustained manner up to $72 \mathrm{~h}$. Although polymeric or block copolymer based vesicles are extensively explored for drug delivery applications, nanovesicles prepared from small bioinspired organic molecule were utilized for drug 
delivery for the first time. We demonstrated that TFN release in vivo at desired time point can be controlled by altering nanovesicles concentration. The mechanism of the drugrelease in vivo is a subject of separate study. Nevertheless, current experiment undoubtfully demonstrated possibility of nanovesicles application as sustained-release drug delivery system.

\section{Conflict of Interests}

The authors declare that there is no conflict of interests regarding the publication of this paper.

\section{Authors' Contribution}

Ajay Kumar Botcha and Balakrishna Dulla contributed equally to this work.

\section{Acknowledgments}

This work was supported by DST (Fast Track Scheme no. SR/FT/CS-083/2009), New Delhi. AKB and ERR thank CSIRNew Delhi for SRFs.

\section{References}

[1] E. Soussan, S. Cassel, M. Blanzat, and I. Rico-Lattes, "Drug delivery by soft matter: matrix and vesicular carriers," Angewandte Chemie-International Edition, vol. 48, no. 2, pp. 274288, 2009.

[2] O. C. Farokhzad and R. Langer, "Impact of nanotechnology on drug delivery," ACS Nano, vol. 3, no. 1, pp. 16-20, 2009.

[3] R. Langer, "New methods of drug delivery," Science, vol. 249, no. 4976, pp. 1527-1533, 1990

[4] F. Zhao, M. L. Ma, and B. Xu, "Molecular hydrogels of therapeutic agents," Chemical Society Reviews, vol. 38, no. 4, pp. 883-891, 2009.

[5] J. Du and R. K. O’Reilly, "Advances and challenges in smart and functional polymer vesicles," Soft Matter, vol. 5, no. 19, pp. 35443561, 2009.

[6] S. K. Sahoo and V. Labhasetwar, "Nanotech approaches to drug delivery and imaging," Drug Discovery Today, vol. 8, no. 24, pp. 1112-1120, 2003.

[7] Q. Duan, Y. Cao, Y. Li et al., "PH-responsive supramolecular vesicles based on water-soluble pillar[6]arene and ferrocene derivative for drug delivery," Journal of the American Chemical Society, vol. 135, no. 28, pp. 10542-10549, 2013.

[8] D. Shi, "Integrated multifunctional nanosystems for medical diagnosis and treatment," Advanced Functional Materials, vol. 19, no. 21, pp. 3356-3373, 2009.

[9] G. P. Kumar and P. Rajeshwarrao, "Nonionic surfactant vesicular systems for effective drug delivery an overview," Acta Pharmaceutica Sinica B, vol. 1, no. 4, pp. 208-219, 2011.

[10] S. C. Jang, O. Y. Kim, C. M. Yoon, D. S. Choi, T. Y. Roh, and J. Park, "Bioinspired exosome-mimetic nanovesicles for targeted delivery of chemotherapeutics to malignant tumors," ACS Nano, vol. 7, no. 9, pp. 7698-7710, 2013.
[11] L. Gao, L. Shi, W. Zhang et al., "Polymerization of spherical poly(styrene-b-4-vinylpyridine) vesicles to giant tubes," Macromolecules, vol. 38, no. 11, pp. 4548-4550, 2005.

[12] Y. S. L. V. Narayana and R. Chandrasekar, "Triple emission from organic/inorganic hybrid nanovesicles in a single excitation," ChemPhysChem, vol. 12, no. 13, pp. 2391-2396, 2011.

[13] G. Zoppellaro and M. Baumgarten, "One-step synthesis of symmetrically substituted 2,6-bis(pyrazol-1-yl) pyridine systems," European Journal of Organic Chemistry, vol. 2005, no. 14, pp. 2888-2892, 2005.

[14] Y. S. L. V. Narayana, S. Basak, M. Baumgarten, K. Müllen, and R. Chandrasekar, "White emitting conjugated polymer/inorganic hybrid spheres: phenylethynyl and 2,6-bis (pyrazolyl)pyridine copolymer coordinated to Eu (tta) $)_{3}$, Advanced Functional Materials, vol. 23, no. 47, pp. 5875-5880, 2013.

[15] E. Khaled, "Spectrophotometric determination of terfenadine in pharmaceutical preparations by charge-transfer reactions," Talanta, vol. 75, no. 5, pp. 1167-1174, 2008.

[16] A. A. Al-Majed, J. Al-Zehouri, and F. Belal, "Use of mixed anhydrides for the determination of terfenadine in dosage forms and spiked human plasma," Journal of Pharmaceutical and Biomedical Analysis, vol. 23, no. 2-3, pp. 281-289, 2000.

[17] A. Schroeder, J. Kost, and Y. Barenholz, "Ultrasound, liposomes, and drug delivery: principles for using ultrasound to control the release of drugs from liposomes," Chemistry and Physics of Lipids, vol. 162, no. 1-2, pp. 1-16, 2009.

[18] G. D. Pangu, K. P. Davis, F. S. Bates, and D. A. Hammer, "Ultrasonically induced release from nanosized polymer vesicles," Macromolecular Bioscience, vol. 10, no. 5, pp. 546-554, 2010.

[19] R. K. Banote, S. Koutarapu, K. S. Chennubhotla, K. Chatti, and P. Kulkarni, "Oral gabapentin suppresses pentylenetetrazoleinduced seizure-like behavior and cephalic field potential in adult zebrafish," Epilepsy and Behavior, vol. 27, no. 1, pp. 212219, 2013.

[20] M. Westerfield, The Zebrafish Book. A Guide for the Laboratory Use of Zebrafish (Danio rerio), University of Oregon Press, Eugene, Ore, USA, 4th edition, 2000.

[21] A. Nakhi, M. S. Rahman, G. P. K. Seerapu et al., "Transition metal free hydrolysis/cyclization strategy in a single pot: synthesis of fused furo N- heterocycles of pharmacological interest," Organic and Biomolecular Chemistry, vol. 11, no. 30, pp. 49304934, 2013.

[22] J. M. Panzica-Kelly, C. X. Zhang, T. L. Danberry et al., "Morphological score assignment guidelines for the dechorionated zebrafish teratogenicity assay," Birth Defects Research BDevelopmental and Reproductive Toxicology, vol. 89, no. 5, pp. 382-395, 2010.

[23] J. Milton Harris and R. B. Chess, "Effect of pegylation on pharmaceuticals," Nature Reviews Drug Discovery, vol. 2, no. 3, pp. 214-221, 2003.

[24] S. Basu and C. Sachidanandan, "Zebrafish: a multifaceted tool for chemical biologists," Chemical Reviews, vol. 113, no. 10, pp. 7952-7980, 2013.

[25] E. R. Reddy, R. K. Banote, K. Chatti, P. Kulkarni, and M. S. Rajadurai, "Selective Multicolour Imaging of Zebrafish Muscle Fibres by Using Fluorescent Organic Nanoparticles," ChemBioChem, vol. 13, no. 13, pp. 1889-1894, 2012. 
[26] P. K. Chan, C. C. Lin, and S. H. Cheng, "Noninvasive technique for measurement of heartbeat regularity in zebrafish (Danio rerio) embryos," BMC Biotechnology, vol. 9, article 11, 2009.

[27] K. Fu, R. Harrell, K. Zinski et al., "A potential approach for decreasing the burst effect of protein from PLGA microspheres," Journal of Pharmaceutical Sciences, vol. 92, no. 8, pp. 1582-1591, 2003.

[28] P. B. O'Donnell and J. W. McGinity, "Preparation of microspheres by the solvent evaporation technique," Advanced Drug Delivery Reviews, vol. 28, no. 1, pp. 25-42, 1997. 

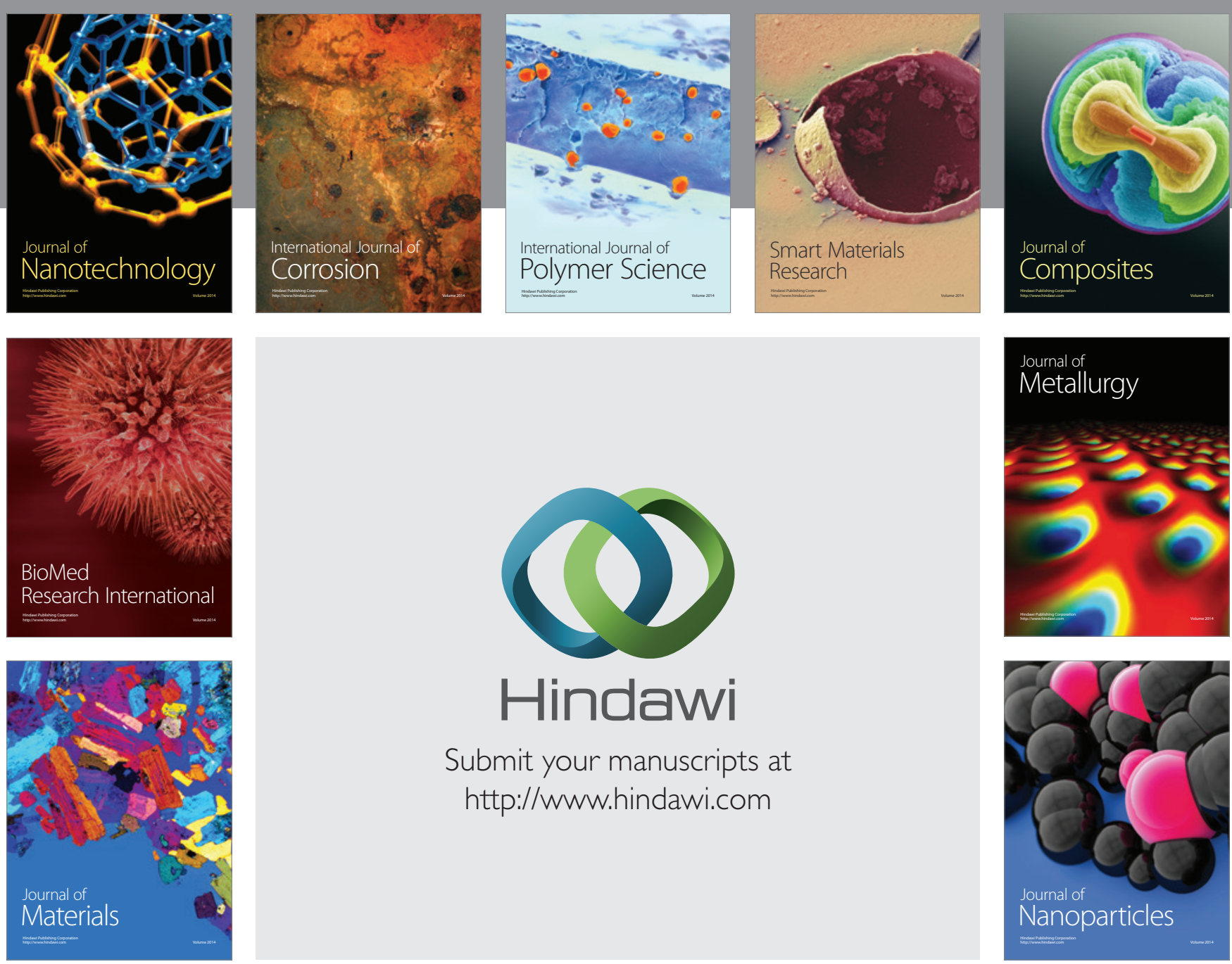

Submit your manuscripts at http://www.hindawi.com
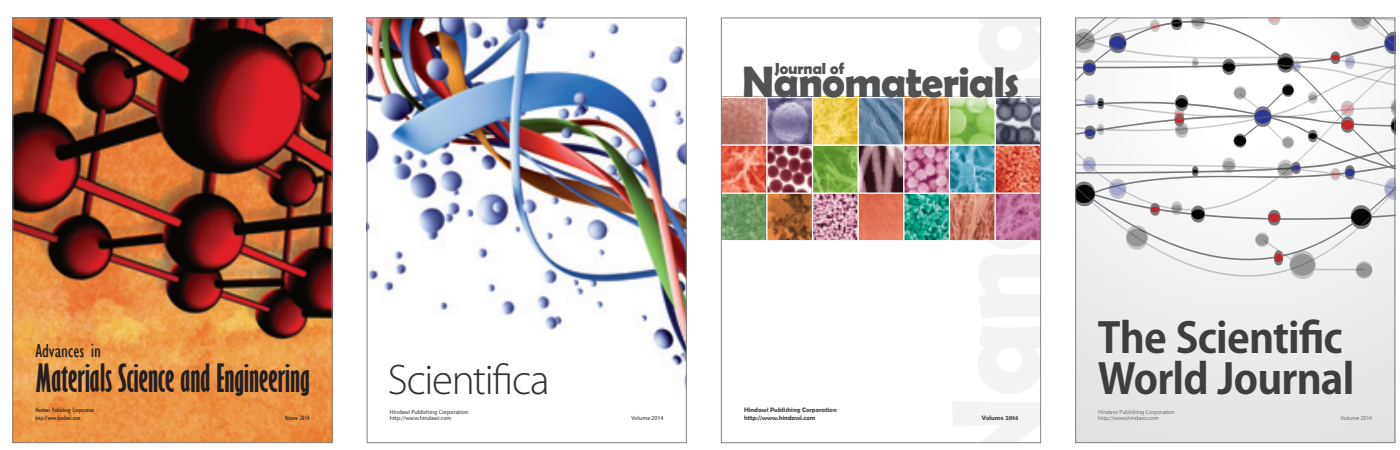

\section{The Scientific World Journal}
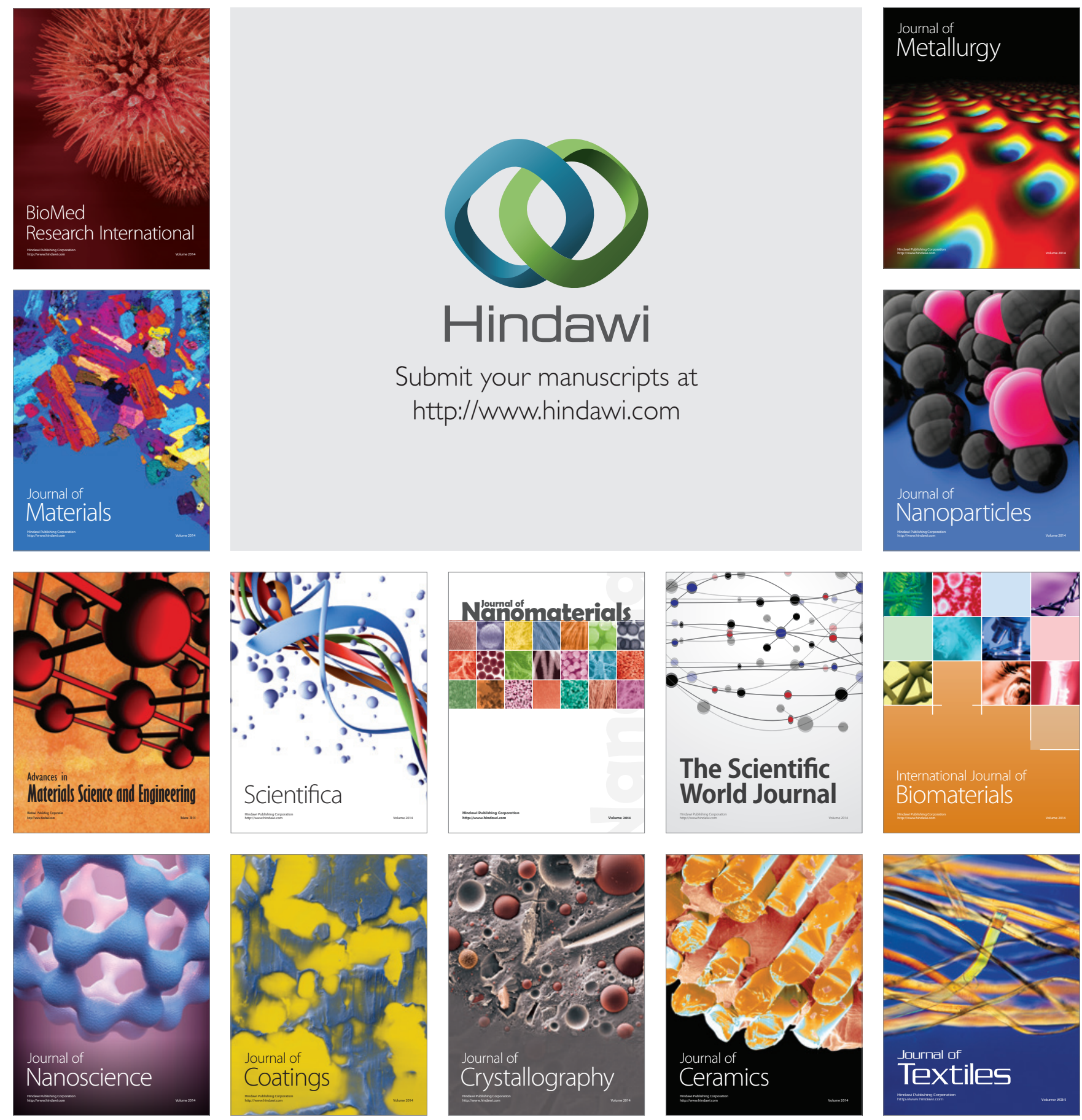